Wright State University

CORE Scholar

3-1-1985

\title{
Summary Abstract: Capacitance-Voltage Characteristics in Modulation Doped Heterojunction FETs
}

\author{
George B. Norris \\ David C. Look \\ Wright State University - Main Campus, david.look@wright.edu \\ W. Koop \\ J. Klem \\ H. Morkoç
}

Follow this and additional works at: https://corescholar.libraries.wright.edu/physics

Part of the Physics Commons

\section{Repository Citation}

Norris, G. B., Look, D. C., Koop, W., Klem, J., \& Morkoç, H. (1985). Summary Abstract: Capacitance-Voltage Characteristics in Modulation Doped Heterojunction FETs. Journal of Vacuum Science \& Technology B, 3 (2), 797-797.

https://corescholar.libraries.wright.edu/physics/170

This Article is brought to you for free and open access by the Physics at CORE Scholar. It has been accepted for inclusion in Physics Faculty Publications by an authorized administrator of CORE Scholar. For more information, please contact library-corescholar@wright.edu. 


\title{
Summary Abstract: Capacitance-voltage characteristics in modulation doped heterojunction FETs
}

\author{
George B. Norris \\ AFWAL/AADR, Wright-Patterson AFB, Ohio 45433 \\ D.C. Look \\ Wright State University, Dayton, Ohio 45435 \\ W. Kopp, J. Klem, and H. Morkoç \\ University of Illinois, Urbana Illinois 61801
}

(Received 15 September 1984; accepted 15 October 1984)

Capacitance-voltage profiling is widely used in the characterization of MBE epilayer growth and is important in the modeling of large-signal FET behavior. In the case of modulation doped $\mathrm{Al}_{x} \mathrm{Ga}_{1}$ - $x$ As/GaAs heterolayers, $C-V$ profiling is complicated by the presence of the two-dimensional electron gas at the heterojunction interface and the resulting overlap of the Schottky and interface depletion regions. As a result, the usual bulk $C-V$ analysis is only applicable for combinations of thicker AlGaAs layers and forward biases where the overlap does not occur and when gate leakage is not a problem. In general for MODFET structures, the overlap does occur and the $C-V$ profile is largely determined by charge control in the $2 \mathrm{D}$ electron gas.

Experimental studies of $n^{+}-\mathrm{Al}_{0.3} \mathrm{Ga}_{0.7} \mathrm{As} / p^{-}-\mathrm{GaAs}$ MODFET structures with doping levels from $1 \times 10^{18}$ to $2.8 \times 10^{18}$ and a variety of gate sizes $\left(100 \times 400\right.$ to $\left.2 \times 100 \mu^{2}\right)$ show that the gate capacitance exhibits three separate regimes of monotonically decreasing behavior with decreasing gate voltage. The first regime is characterized by a substantial decreasing gate leakage current and is attributed to depletion of carriers in the AlGaAs and decreasing forward Schottky leakage. The second is characterized by an increasingly large decrease in capacitance below the nominal gate bias for the overlap of Schottky and interface depletion regions and is attributed to charge control in the 2D electron gas. Below the threshold voltage for occupancy of the 2D gas, a third regime with a very slow decrease is found with widely varying amounts of residual capacitance and is attributed to subthreshold charge control and parasitic capacitances. In addition, variations in the voltages separating these regimes are seen, even between identical devices (variations as large as $0.2 \mathrm{~V}$ ) and are attributed to variability in fabrication.

We have calculated the expected behavior in the last two regimes via a fully self-consistent variational calculation of charge control in the quantized 2D gas with multiple subbands and the inclusion of residual acceptors in the GaAs, series resistance in the conducting channel, contact resistance, and parasitic capacitances. Unlike the constant gate capacitance of semiempirical linear charge control models, the capacitance is seen to initially decrease gradually $(10 \%-$ $15 \%$ ) over the first half of the useful gate voltage swing and then substantially (falling to 5\%-10\%) over the remainder, due to the detailed variation of subband occupancies, energies, and widths and is in good general agreement with the experimental results. There is no evidence of any change in the $C-V$ curve due to increasing occupancy of higher subbands with voltage.

The effects of channel series resistance were seen in the longer gate length devices (lengths greater than $10 \mu$ ) at room temperature as an increase in the parallel conductance measured near the gate threshold voltage and were in excellent agreement with the theory and the estimated electron mobility $\left(5-8 \times 10^{3} \mathrm{~cm}^{2} / \mathrm{V} \mathrm{S}\right)$. There was no evidence of $C-V$ distortion due to contact resistance (generally $2-40 \Omega \mathrm{mm}$ ) and the calculation predicted none (until resistances exceed 400 $\Omega \mathrm{mm}$ at lengths of $100 \mu$ and frequencies of $1 \mathrm{MHz}$ ). Residual parasitic capacitances varied widely between identical devices (from $1 \%$ to $20 \%$ of the maximum expected capacitance) and are ascribed to variations in device fabrication.

The analysis of $C-V$ profiles can be performed either by direct inversion of the measured data to yield the 2D gas density as a function of gate voltage or by fitting of the theoretical curves to the data. In cases where series resistance is unimportant, direct integration of the $C-V$ data corrected by subtraction of residual capacitance, yielded reasonable 2D carrier concentrations up to where occupation of the doping layer becomes important. We show that inversion of the data is possible even when series resistance is important, by determining the phase of the complex admittance via a simultaneous measurement of gate capacitance and conductance. However, in practice, this is quite difficult due to residual capacitance and conductance near the threshold voltage where the method is most applicable and the sensitive nature of the inversion method. Fitting of theory to experiment can yield information on $\mathrm{AlGaAs}$ composition, thickness, and doping, as well as limts on the mobility in the conducting channel, although the interrelated nature of these parameters makes accurate individual determination difficult. 